\title{
A QUASI REAL-TIME APPROACH TO INVESTIGATING THE DAMAGE AND FRACTURE PROCESS IN PLAIN CONCRETE BY X-RAY TOMOGRAPHY
}

\author{
Qin YUAN ${ }^{\mathrm{a}}$, Chai JUNRUI ${ }^{\mathrm{a}}$, b , Ding WEIHUA ${ }^{\mathrm{a}}$, Dang FANING ${ }^{\mathrm{a}}$, \\ Lei MAN ${ }^{\mathrm{a}}$, Xu ZENGGUANG ${ }^{\mathrm{a}}$ \\ ${ }^{a}$ State Key Laboratory of Eco-Hydraulic Engineering in Shaanxi, \\ Xi'an University of Technology, 710048 Xi'an, China \\ ${ }^{b}$ College of Civil and Hydropower Engineering, China Three Gorges University, \\ Yichang, 443002 Hubei, China
}

Received 16 Apr 2013; accepted 16 Sep 2013

\begin{abstract}
In most concrete-related computer tomography (CT) experiments, detailed information on the damage and fracture process is obtained using nonreal-time approaches, with the CT method constantly regarded as a qualitative method. This study develops a quasi real-time method with the use of experimental instruments. The average CT number is used to analyse the damage and fracture process in concrete specimens and the theory that underlies concrete damage and fracture is improved. Various characteristics of the fracture form in different loading cases are investigated at the macro and micro levels. This study provides a convenient and fast method for qualitatively and quantitatively analysing concrete.
\end{abstract}

Keywords: concrete, X-ray computed tomography, damage, medical computed tomography, compression.

\section{Introduction}

Concrete is critical to the construction of buildings and has been studied for many years. Given the complex internal structures of concrete, the relationship between its microstructure and mechanical properties remains inadequately understood. Several techniques have been used to non-destructively investigate concrete materials. Such procedures include the acoustic emission (AE) method, computer tomography (CT), the nonlinear ultrasonic (NLU) method (Chai et al. 2011), elastic wave method (Kocur et al. 2010; Langenberg et al. 2006), and the digital laminography method (Wakimoto et al. 2008). Of these, AE and CT are the most extensively applied.

$\mathrm{AE}$, which is capable of real-time damage monitoring (Degala et al. 2009), has potential applications in monitoring material integrity. Sagar and Prasad (2011a, 2011b) conducted $\mathrm{AE}$ experiments to investigate the fracture energy of a concrete specimen, after which they combined the numerical simulation method with $\mathrm{AE}$ and discussed damage distributions in concrete. Rossi et al. (2012) used AE to investigate the basic creep behaviour of concrete. Shah and Ribakov (2010) combined two non-destructive evaluation methods (AE and NLU) to discuss crack distribution. AE techniques have also been used to study the fracture behaviour of concrete - concrete interfaces (Shah et al. 2010). Although the AE method can more rapidly, accurately and quantitatively detect internal cracks than can other methods, one of its disadvantages is that the volume of entire instruments (including the loading instrument) is large. Thus, this approach cannot visualise cracks as images and does not produce detailed information (e.g. form or width of cracks) on the concrete damage process.

The CT technique, commonly used in medical applications, may be a good approach to non-destructive concrete research. CT machines can be categorised into industrial and medical types (Ding et al. 2009). The CT method is often used to evaluate cracks in concrete specimens. Using CT and AE methods, Elaqra et al. (2007) identified the mechanisms of damage and the fracture process during compressive loading on concrete specimens. A 3D concrete specimen was reconstructed using CT images, and the damage parameter was discussed (Wang et al. 2003), and Suzuki et al. (2010) used the same method to evaluate the damage in freeze-thawed concrete. De Graef et al. (2005) used X-ray microtomography to analyse bacterial weathering in concrete. Man and van Mier (2011) obtained the structure of concrete prism aggregates using the CT method and then built a numerical model to investigate the damage distribution and size effects of

Corresponding author: Chai Junrui

E-mail:jrchai@xaut.edu.cn 
the concrete prism. Wong and Chau (2005) estimated the air void and aggregate distribution in normal- and highstrength concrete specimens at various loading cases using CT. The perviousness of concrete was assessed by Kayhanian et al. (2012) using CT scanning, X-ray tomography imaging and image analysis. The assessments were used to reconstruct actual aggregate shapes (Wang et al. 2007). Braz et al. (2007) demonstrated the feasibility of using CT to study concrete paving. Garboczi (2002) combined X-ray tomography with spherical harmonics and subsequently analysed the shape of concrete particles.

Most studies use industrial CT machines, which have mediocre scanning speeds and high rental costs. To satisfy the needs of practical applications, we select a medical CT machine for use in our study, thereby reducing cost and time of experimentation. However, one of the disadvantages of medical CT machines is that the CT bed cannot bear much weight and has a very limited width. Therefore, designing a new test machine suitable for medical CT is necessary. The test machine, also called a portable test machine (PTM), must be small and lightweight.

A PHILIPS 16 helical CT scanner was used in the experiment. The maximum bearing capacity of its $\mathrm{CT}$ bed is $300 \mathrm{~kg}$ and its width is $0.32 \mathrm{~m}$. The scanning diameter is $\phi 0.75 \mathrm{~m}$. On the basis of these parameters, we design a PTM for our experiment, on which detailed information is provided in Section 1.

The PTM is tested and the results are shown in Figure 1. We obtain the CT number of every red and cyan point in the figure, and draw a point-CT number curve beside the plot.

Figure 1 shows the different grey levels corresponding to various $\mathrm{CT}$ numbers, as well as the different $\mathrm{CT}$ numbers associated with the density of internal concrete material. For example, along the red and cyan lines, the $\mathrm{CT}$ number of the aggregate is large and the colour in the CT image is close to white. By contrast, the CT numbers of the cracks or holes are very small and the colour in the CT image is black or nearly black. Cement mortar is found around the aggregates and the density of this region is lower than that of the aggregates but larger than that of the cracks and holes. Thus, its colour is light or dark grey. As the test continues, the number of cracks gradually increases and the average CT number of the section gradually decreases. On the basis of this property of the CT images, the relationship between CT number and load can be used to investigate the quantitative and qualitative details of the cracking process of concrete specimens.

This study presents detailed information regarding our test machine, as well as the difficulties encountered during the experiment. CT images and $\mathrm{CT}$ numbers are used to discuss the different damage processes under static and dynamic loading.

\section{Specimen, instruments, and challenges}

\subsection{Specimen}

The size of the specimen used in our experiment was $\phi$ $60 \times 120 \mathrm{~mm}$. The grading curve and a photograph of the specimen are shown in Figure 2.

\subsection{Instruments}

The PTM consists of three main parts (Fig. 3): a piston loading equipment (PLE), hydraulic actuator machine (HAM), and external digital controller (EDC).

\section{A. Piston loading equipment}

To achieve high strength and low X-ray absorption rates, we chose aluminous alloy as the material for the PLE shell. The structure of the PLE is shown in Figure 4. The PLE is a self-balanced system, thereby enabling the satisfaction of low weight and small volume requirements. In the experiment, the PLE was fixed to the CT bed by a steel base plate. The total weight of the PLE (including the concrete specimen) was around $90 \mathrm{~kg}$; three people can easily move this equipment.

\section{B. Hydraulic actuator machines}

The experimental load was produced by HAMs. The loads ranged from 0 to $100 \mathrm{kN}$, and the confining pressures ranged from 0 to $5 \mathrm{MPa}$. A NACHI high-pressure gear pump was used to reduce noise levels and harmful vibra-

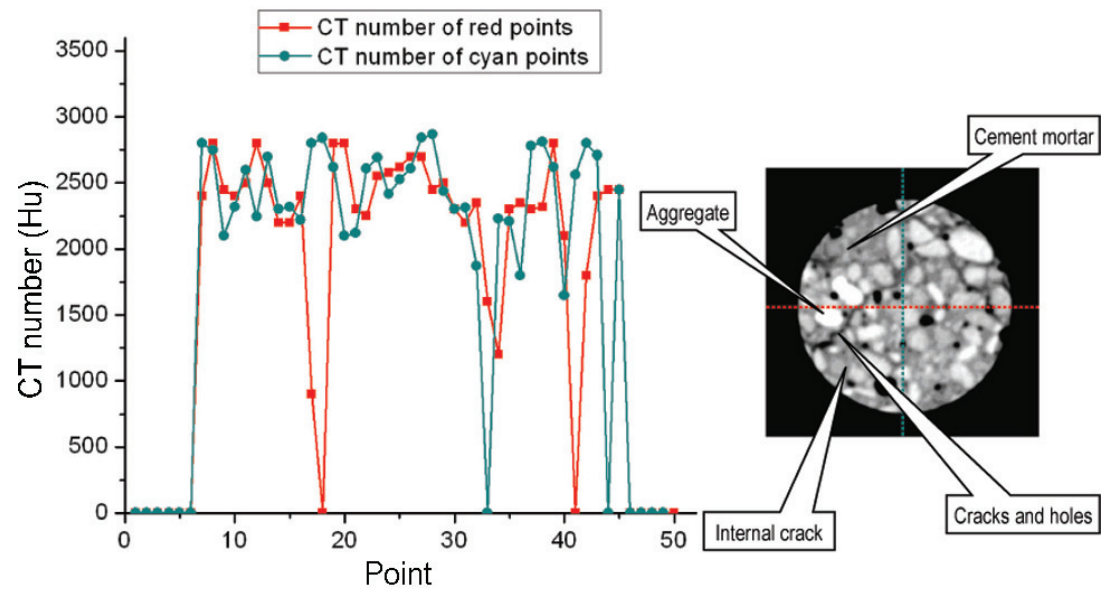

Fig. 1. Point-CT number curve and CT image 
(A)

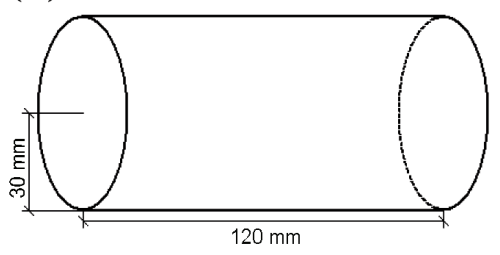

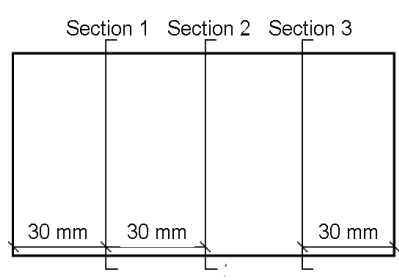

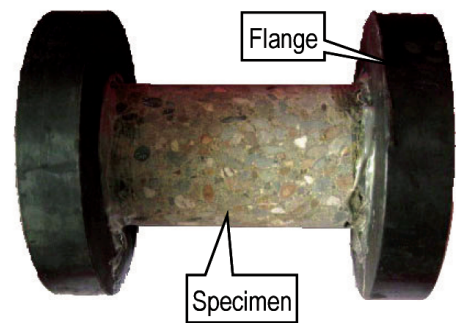

(B)

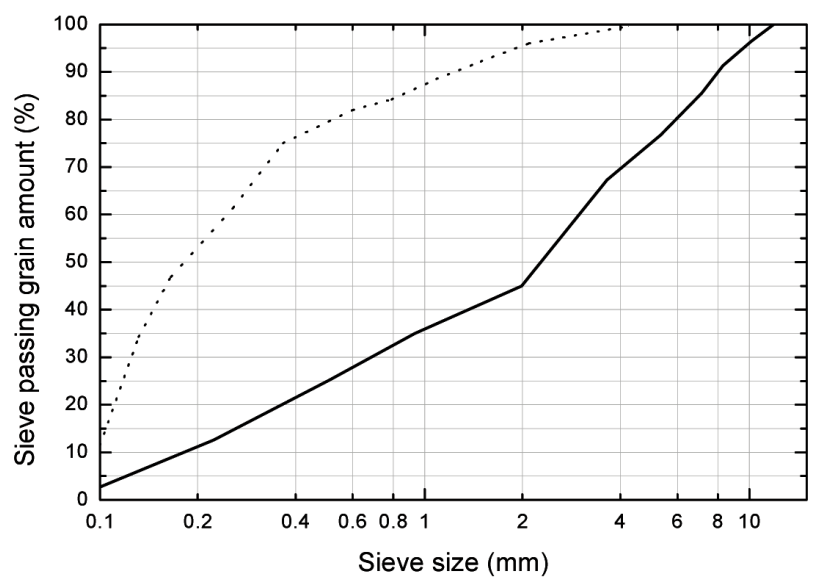

Fig. 2. Geometry of the experimental concrete specimen: a) geometry (left), section position (middle) and photograph (right); b) grading curve for sand (discontinuous line) and gravel (continuous line) used for the concrete specimens

tions. A water-cooling system was fixed to the HAMs to ensure machine operation at normal temperatures.

\section{External digital controller}

The EDC (DOLI Company, Germany), which has two control modes (load and displacement) was connected to a computer. A significant advantage of the EDC is that it can alternate between these two control modes shock-free. Moreover, the loading case can easily be changed during experiments (e.g. constant pressure, constant rate, sinusoidal wave, triangular wave, trapezoidal wave, square wave, etc.). follows:

The advantages of this experimental setup are as

a) The PTM consists of three parts, each with a small volume and weight. Thus, the machine can be moved easily, resulting in simpler experimental processes.

b) Compared with industrial $\mathrm{CT}$ machines, medical $\mathrm{CT}$ machines are highly efficient and consume less energy.

c) Quasi real-time monitoring enables the observation of the evolution of cracks in various concrete sections.

d) With the experiment, we can obtain qualitative and quantitative results from $\mathrm{CT}$ images and $\mathrm{CT}$ numbers, respectively.

\subsection{Challenges}

This experiment is a quasi-real-time experiment mainly because of the method used. In the experiment, the CT machine needed time to scan an entire specimen and loading needed to be stopped during scanning. If loading was continued whilst performing a scan, the internal structure of the concrete specimen would change during the scanning period; thus, obtaining a CT image corresponding to the exact value of the load would be difficult. We used the displacement control mode of the EDC to keep the transient displacement unchanged. After scanning, the EDC was switched back to the load control mode and loading was resumed. We call this method the freezing method.

An important issue that must be considered is stress relaxation. During loading, stress relaxation becomes more apparent, particularly when load value approaches the peak load of a concrete specimen (Ding et al. 2009). To test the rationality of the freezing method, we created a test plan as follows:

a) We chose two concrete specimens labelled Test specimen_1 and Test specimen_2.

b) The specimens were loaded and scanned in accordance with the freezing method, with loading values of $30 \%, 60 \%$ and $90 \%$ of the predicted peak load value.

c) After each loading step, the loading was terminated, keeping instant displacement constant. The specimens were then scanned three times at 0.5 , and $10 \mathrm{~min}$. Afterwards, we extracted the average CT number derived from Section 2 (Fig. 2(A)) and compared the results (Fig. 5).

Figure 5 shows that the CT numbers at $30 \%$ and $60 \%$ loading slightly change before the 5 -min mark. At $90 \%$ loading, the CT number slightly changes before the 3 -min mark but drastically changes at $5 \mathrm{~min}$. Overall, 

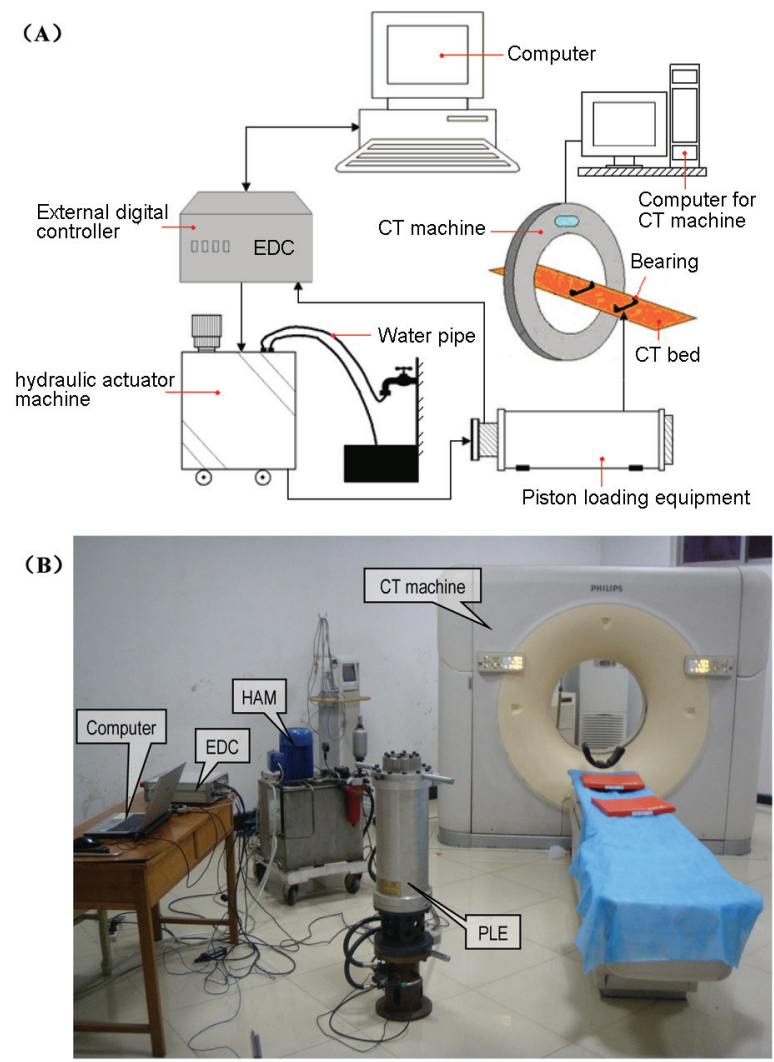

Fig. 3. Experimental setup: a) arrangement of testing instruments; b) photograph of the instrument layout

the effects of stress relaxation are insignificant before the 3-min mark. Moreover, the effects of stress relaxation are imperceptible after loading was terminated. Thus, the average CT number only slightly changes, indicating that cracks and holes do not evolve after loading is stopped.

After about $7 \mathrm{~min}$, the CT number drastically decreases. Cracks and holes appear during this period and the effects of stress relaxation become noticeable. The results indicate that the effects of stress relaxation become more evident as loading increases. Thus, we should ensure that the specimens can be scanned within about 3 min or shorter. At most, $50 \mathrm{~s}$ is required to scan an en-

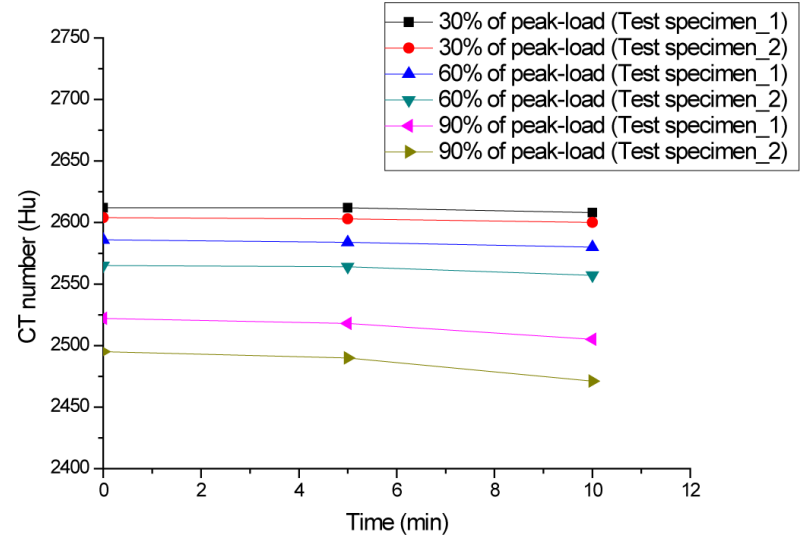

Fig. 5. Time-CT number curves of Test specimen 1 and Test specimen_2 with loads of $30 \%, 60 \%$ and $90 \%$ of the predicted peak load value

tire specimen and continue loading, indicating that stress relaxation can be disregarded and the freezing method is rational.

\section{Results and discussion}

CONC_01 and CONC_06 were the specimens used in this experiment. Two different loading cases were studied (Table). The average CT number - stress curves of CONC_01 and CONC_06 are shown in Figure 6.

A number of traditional viewpoints (Tian et al. 2009; Qin et al. 2013) hold that the damage process of concrete specimens can be divided into three stages: the elastic stage, crack development stage, and complete damage stage. However, Figure 6 shows that these traditional viewpoints may not entirely be accurate. Given that concrete is a man-made non-homogeneous material, at the beginning of the experiment $(\mathrm{OA})$, the average $\mathrm{CT}$ number of each section (the position of each section is shown in Fig. 2) is approximately $2600 \mathrm{Hu}$. The concrete specimens are in the elastic stage and the CT number minimally changes.

With increasing load, the average $\mathrm{CT}$ numbers show increasing trends $(\mathrm{AB})$. For example, in Section 1 of CONC 01 (Fig. 6), the average CT number increases

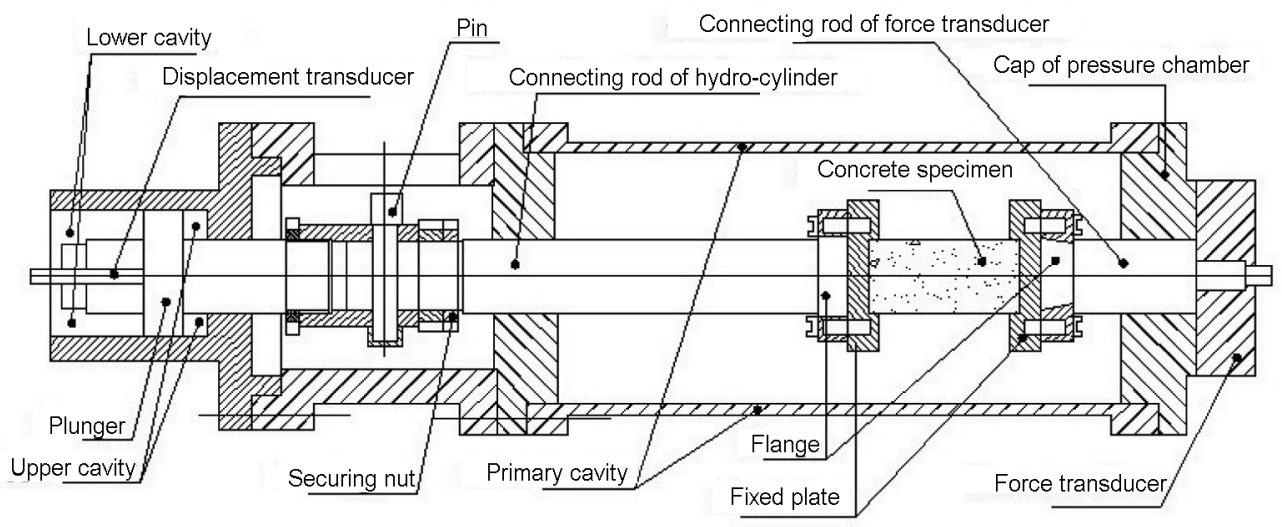

Fig. 4. Interior structure of the PLE 
Table. Loading case

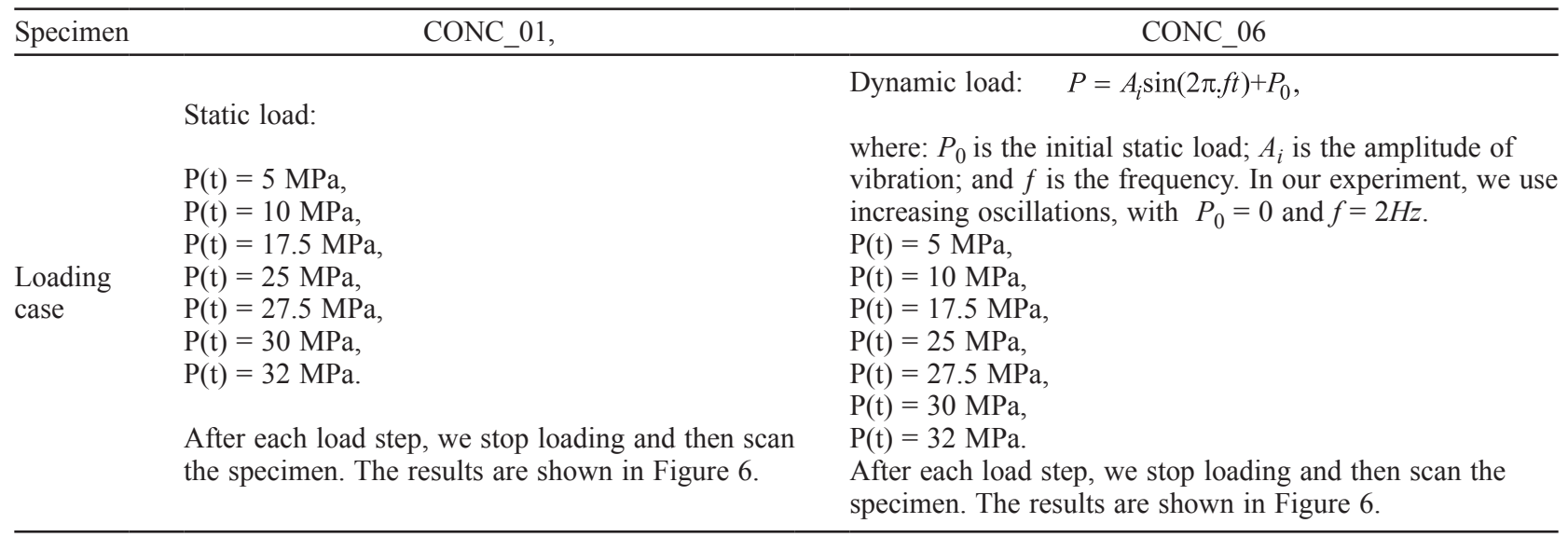
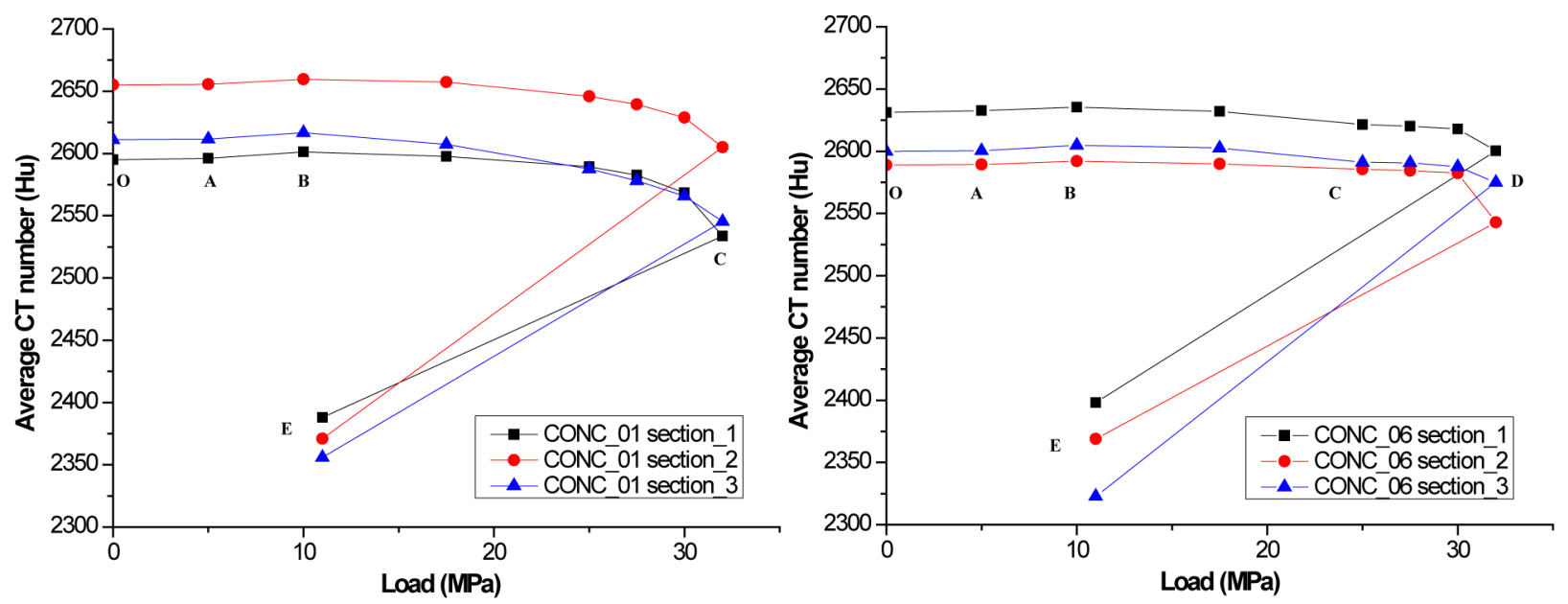

Fig. 6. Load-average CT number curves of the static (left) and dynamic (right) loads

from 2589 to $2603 \mathrm{Hu}$. The same phenomenon was observed in the other sections and CONC_06. This increasing trend indicates that the average density of a concrete specimen increases because the volumes of some internal cracks and holes in the specimen are compressed. We consider this trend as indicative of the consolidation stage. After this stage, the average CT number gradually drops with loading (BC), indicating that cracks form in the concrete. This stage is classified as the crack development stage.

After the crack development stage, the differences between the static and dynamic loading cases were observed. In CONC_06, increasing the load on the specimens clearly results in a short stable stage after the crack development stage. This short stage is regarded as the stable stage $(\mathrm{CD})$ because the average $\mathrm{CT}$ number barely changes with load (e.g. the average CT number changes from 2582 to $2579 \mathrm{Hu}$ ). In CONC_01, however, this stage was not observed.

From the perspective of energetics, in the static loading case, long-term loading means that energy has sufficient time to dissipate. Cracks then gradually enlarge as the average CT numbers decrease, which is the most important characteristic of the static loading case. The curve in Figure 6 indicates a downward trend after the $\mathrm{AB}$ stage. In the dynamic loading case, however, shortterm loading means that energy does not have sufficient time to dissipate. Instead, energy becomes concentrated for a short period and then quickly dissipates. Thus, the average CT number suddenly drops, which is why the stable stage was observed only in the dynamic loading case.

Finally, with continuous loading, the specimens are completely damaged (CE in the static loading case, DE in the dynamic loading case), leading to a drastic decrease in $\mathrm{CT}$ number.

Figure 7 shows the CT images of Section_2 for each point in the curve shown in Figure 6. In the elastic stage $(\mathrm{OA})$, the initial cracks and holes in the concrete specimen can be clearly seen and no obvious cracks appear. In the consolidation stage (AB), the volumes of some of the cracks and holes subsequently decrease and no apparent cracks form. Although these features cannot be clearly observed in the $\mathrm{CT}$ images, these features can 
be seen in Figure 6. With increasing load, the consolidation stage is complete and the crack development stage (BC) begins. In this stage, a number of obvious cracks form and the instantaneous strength levels of the static and dynamic loading cases are 17.8 and $18.6 \mathrm{MPa}$, respectively. Some cracks are connected to each other and most new cracks are generated in the cement mortar.

After the crack development stage, an obvious difference between the two loading cases was observed. In the static loading case, the volume of cracks continues to increase, whereas in the dynamic loading case, a stable stage (CD) occurs. A significant feature of the stable stage is that the cracks slowly developed and the said state lasts for a short period.

The complete damage stages of the static and dynamic loading cases differ from each other. In the static loading case, the cracks remain around the aggregate and the path of the cracks is curved (Fig. 7a). When the specimen is damaged, an obvious $45^{\circ}$ main crack that cuts the specimen into two parts was observed (Fig. 8a). Some aggregates also emerge from the cut surface. The surface of these aggregates is rough and lacklustre, and some cement mortars adhere to it (Fig. 9a), indicating that the aggregate is not cut.
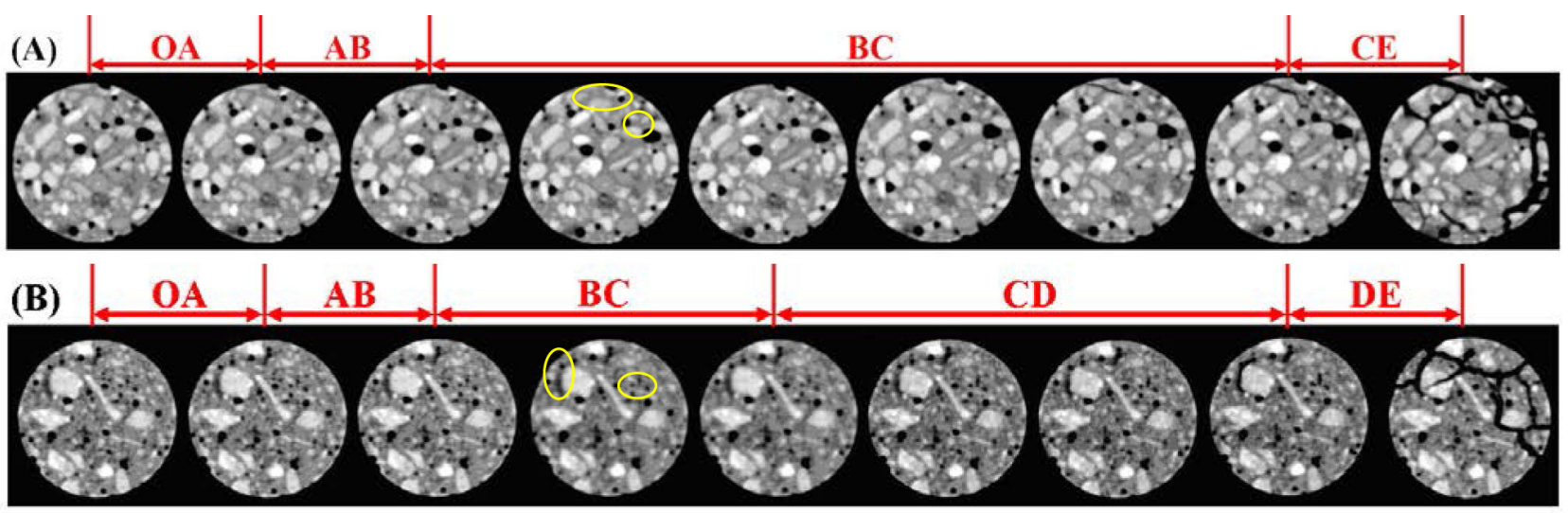

Fig. 7. CT images of the (A) (CONC_01) static and (B) (CONC_06) dynamic loading cases (yellow circles indicate the positions of initial cracks)
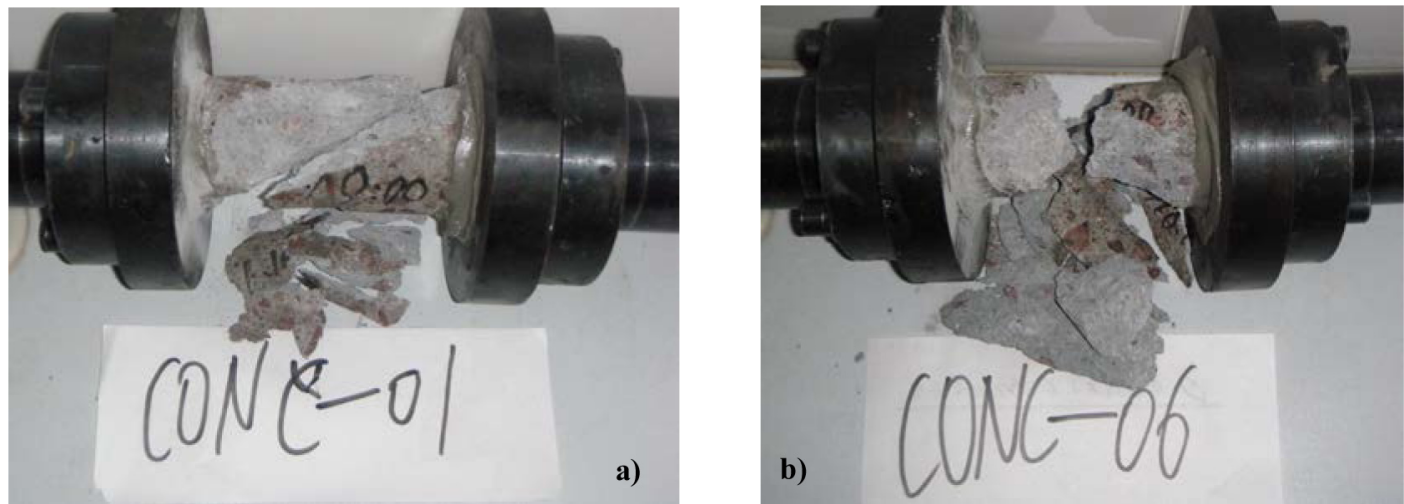

Fig. 8. Photograph of the final damage stage: a) CONC_1 in the static loading case; b) CONC_6 in the dynamic loading case
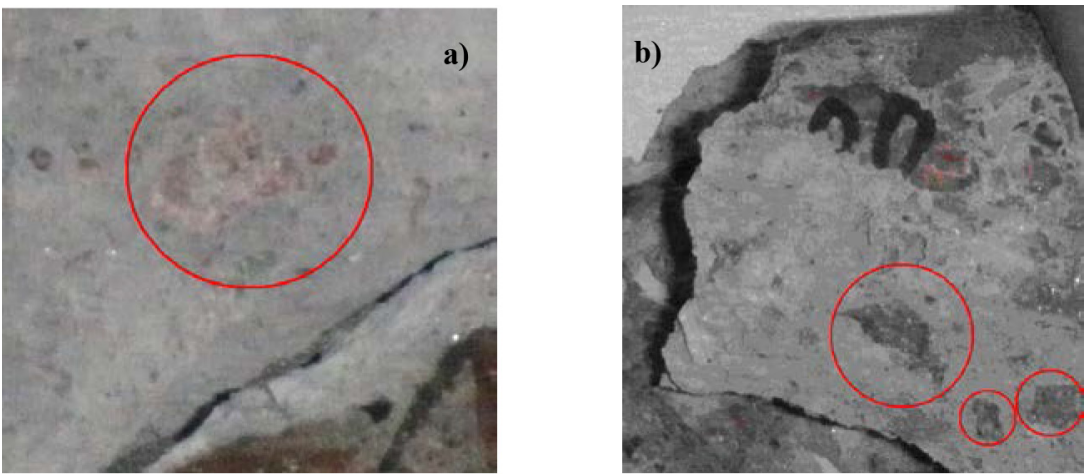

Fig. 9. Detailed images of CONC_01 and CONC_06 
In the dynamic loading case, a number of main cracks pass though the aggregate and most crack paths are straight (Fig. 7b). When the specimen is damaged, no obvious main crack occurs, but the specimen is broken into pieces (Fig. 8b). The surface of the aggregate, which emerges from the damaged surface, is smooth and glossy without any adhering cement mortars (Fig. 9b), suggesting that the aggregate is cut by the cracks.

\section{Conclusions}

In this study, a PTM suitable for medical CTs was developed and two loading cases were tested. Concrete damage and fracture theory was improved on the basis of the experimental results. The conclusions drawn are summarised as follows:

(1) The PTM works well with the medical CT machine. As indicted in the freezing method, the effect of stress relaxation on concrete can be disregarded. The experimental process is easy to control and the proposed procedure is suitable for engineering applications given its low cost.

(2) In both the static and dynamic loading cases, a consolidation stage in the experimental process was observed. However, differences also exist between the static and dynamic loading processes. In the dynamic loading case, an obvious stable stage occurs before the complete damage stage. In this stage, the average CT number barely changes. By contrast, in the static loading case, cracks gradually develop with load and the average CT number gradually decreases.

(3) The complete damage stages of the static and dynamic loading cases differ from each other. In the static loading case, a $45^{\circ}$ main crack that cuts through the specimen was observed. In the dynamic loading case, no obvious main crack was seen in the specimen because it is broken into pieces.

\section{Acknowledgments}

This study was financially supported by Research Fund for the Doctoral Program of Higher Education of Xi' an University of technology 106-211306, the National Science Foundation for Distinguished Young Scholars of China (No. 51409208), the National Science Foundation for Post-doctoral Scientists of China (No. 2014M562524XB), the Research Foundation of Education Bureau of Hunan, China (No. 14JK1514), and Shaanxi provincial key innovative research team (2013KCT-15)

\section{References}

Braz, D.; Almeida, P. E. S.; Motta, L. M. G.; Barroso, R. C.; Lopes, R. T. 2007. Study of the concrete overlay (whitetopping) in paving using computed tomographic system, Nuclear Instruments and Methods in Physics Research A 579(1): 510-513. http://dx.doi.org/10.1016/j.nima.2007.04.112

Chai, H. K.; Momoki, S.; Kobayashi, Y.; Aggelis, D. G.; Shiotani, T. 2011. Tomographic reconstruction for concrete using attenuation of ultrasound, NDT\&E International 44(2): 206-215.

http://dx.doi.org/10.1016/j.ndteint.2010.11.003

Degala, S.; Rizzo, P.; Ramanathan, K.; Harries, K. A. 2009. Acoustic emission monitoring of CFRP reinforced concrete slabs, Construction and Building Materials 23(5): 2016-2026.

http://dx.doi.org/10.1016/j.conbuildmat.2008.08.026

Ding, W.; Chen, H.; Yin, X.; Liu, S.; Zhang, J.; Feng, Y. 2009. Study of key techniques of dynamic loading CT test device for rock-like material, Chinese Journal of Rock Mechanics and Engineering 28(8): 1620-1628.

Elaqra, H.; Godin, N.; Peix, G.; R'Mili, M.; Fantozzi, G. 2007. Damage evolution analysis in mortar, during compressive loading using acoustic emission and X-ray tomography: effects of the sand/cement ratio, Cement and Concrete Research 37(5): 703-713.

http://dx.doi.org/10.1016/j.cemconres.2007.02.008

Garboczi, E. J. 2002. Three-dimensional mathematical analysis of particle shape using X-ray tomography and spherical harmonics: application to aggregates used in concrete, Cement and Concrete Research 32(10): 1621-1638. http://dx.doi.org/10.1016/S0008-8846(02)00836-0

De Graef, B.; Cnudde, V.; Dick, J.; De Belie, N.; Jacobs, P.; Verstraete, W. 2005. A sensitivity study for the visualisation of bacterial weathering of concrete and stone with computersied X-ray microtomography, Science of the Total Environment 341(1-3): 173-183.

http://dx.doi.org/10.1016/j.scitotenv.2004.09.035

Kayhanian, M.; Anderson, D.; Harvey, J. T.; Jones, D.; Muhunthan, B. 2012. Permeability measurement and scan imaging to assess clogging of pervious concrete pavements in parking lots, Journal of Environmental Management 95(1): 114-123. http://dx.doi.org/10.1016/j.jenvman.2011.09.021

Kocur, G. K.; Saenger, E. H.; Vogel, T. 2010. Elastic wave propagation in a segmented X-ray computed tomography model of a concrete specimen, Construction and Building Materials 24(12): 2393-2400. http://dx.doi.org/10.1016/j.conbuildmat.2010.05.013

Langenberg, K. J.; Mayer, K.; Marklein, R. 2006. Nondestructive testing of concrete with electromagnetic and elastic waves: modeling and imaging, Cement \& Concrete Composites 28(4): $370-383$. http://dx.doi.org/10.1016/j.cemconcomp.2006.02.010

Man, H.-K.; van Mier, J. G. M. 2011. Damage distribution and size effect in numerical concrete from lattice analyses, Cement \& Concrete Composites 33(9): 867-880. http://dx.doi.org/10.1016/j.cemconcomp.2011.01.008

Qin, Y.; Chai, J.; Dang, F. 2013. Improved random aggregate model for numerical simulations of concrete engineering, Journal of Civil Engineering and Management 19(2): 285-295. http://dx.doi.org/10.3846/13923730.2012.760481

Rossi, P.; Tailhan, J.-L.; Maou, F. L.; Gaillet, L.; Martin, E. 2012. Basic creep behavior of concretes investigation of the physical mechanisms by using acoustic emission, Cement and Concrete Research 42(1): 61-73. http://dx.doi.org/10.1016/j.cemconres.2011.07.011

Sagar, R. V.; Prasad, B. K. R. 2011a. An experimental study on acoustic emission energy as a quantitative measure of size independent specific fracture energy of concrete beams, Construction and Building Materials 25(5): 2349-2357. http://dx.doi.org/10.1016/j.conbuildmat.2010.11.033

Sagar, R. V.; Prasad, B. K. R. 2011b. Fracture analysis of concrete using singular fractal functions with lattice beam network and confirmation with acoustic emission study, Theoretical and Applied Fracture Mechanics 55(3): 192-205. http://dx.doi.org/10.1016/j.tafmec.2011.07.003 
Shah, A. A.; Ribakov, Y. 2010. Effectiveness of nonlinear ultrasonic and acoustic emission evaluation of concrete with distributed damages, Materials and Design 31(8): 3777 3784. http://dx.doi.org/10.1016/j.matdes.2010.03.020

Shah, S. G.; Kishen, J. M. Ch. 2010. Fracture behavior of concrete - concrete interface using acoustic emission technique, Engineering Fracture Mechanics 77(6): 908-924. http://dx.doi.org/10.1016/j.engfracmech.2010.01.018

Suzuki, T.; Ogata, H.; Takada, R.; Aoki, M.; Ohtsu, M. 2010. Use of acoustic emission and X-ray computed tomography for damage evaluation of freeze-thawed concrete, Construction and Building Materials 24(12): 2347-2352. http://dx.doi.org/10.1016/j.conbuildmat.2010.05.005

Tian, W.; Dang, F.; Liang, X.; Chen, H. 2009. CT real-time observation of meso-damage process for concrete material under uniaxial compression, Journal of Experimental Mechanics 24(3): 184-190.

Wakimoto, K.; Blunt, J.; Carlos, C.; Monteiro, P. J. M.; Ostertag, C. P.; Albert, R. 2008. Digital laminography assessment of the damage in concrete exposed to freezing temperatures, Cement and Concrete Research 38(10): 1232-1245. http://dx.doi.org/10.1016/j.cemconres.2008.05.003

Wang, L. B.; Frost, J. D.; ZVoyiadjis, G.; Harman, T. P. 2003. Quantification of damage parameters using Xray tomography images, Mechanics of Materials 35(8): 777-790. http://dx.doi.org/10.1016/S0167-6636(02)00206-5

Wang, L.; Park, J.-Y.; Fu, Y. 2007. Representation of real particles for DEM simulation using X-ray tomography, Construction and Building Materials 21(2): 338-346. http://dx.doi.org/10.1016/j.conbuildmat.2005.08.013

Wong, R. C. K.; Chau, K. T. 2005. Estimation of air void and aggregate spatial distributions in concrete under uniaxial compression using computer tomography scanning, Cement and Concrete Research 35(8): $1566-1576$.

http://dx.doi.org/10.1016/j.cemconres.2004.08.016

Qin YUAN. $\mathrm{PhD}$, the Institute of Water Resources and Hydro-electric Engineering of Xi'an University (China). His research interests: the mechanical property of concrete and concrete technology.

Chai JUNRUI. Professor at the Institute of Water Resources and Hydro-electric Engineering of Xi'an University of Technology (China) and College of Civil and Hydropower Engineering of China Three Gorges University (China). His research interests: the mechanical property of concrete and non-linear seepage problem for dam engineering.

Ding WEIHUA. Associate Professor at the Civil Engineering and Architecture of Xi'an University of Technology (China). His research interests: the $\mathrm{CT}$ experiment of concrete material and the problems of engineering geological.

Dang FANING. Professor at the Civil Engineering and Architecture of Xi'an University of Technology (China). His research interests: the mechanical property of concrete and seepage problem for dam engineering.

Lei MAN. Master in the Civil Engineering and Architecture of Xi'an University of Technology (China). Her research interests include the CT experiment of concrete material and meso-damage process for concrete material.

Xu ZENGGUANG. Lecturer of the Institute of Water Resources and Hydro-electric Engineering of Xi'an University (China). His research interests: the environmental and non-linear seepage problem for civil engineering. 